\section{(6) OPEN ACCESS}

\title{
Riociguat for the treatment of pulmonary arterial hypertension associated with connective tissue disease: results from PATENT-1 and PATENT-2
}

\author{
Marc Humbert, ${ }^{1,2,3}$ J Gerry Coghlan, ${ }^{4}$ Hossein-Ardeschir Ghofrani, ${ }^{5,6}$ \\ Friedrich Grimminger, ${ }^{5}$ Jian-Guo He, ${ }^{7}$ Gabriela Riemekasten, ${ }^{8}$ Carmine Dario Vizza, ${ }^{9}$ \\ Annette Boeckenhoff, ${ }^{10}$ Christian Meier, $^{11}$ Janethe de Oliveira Pena, ${ }^{12}$ \\ Christopher P Denton ${ }^{13}$
}

Handling editor Tore K Kvien

- Additional material is published online only. To view please visit the journal online (http://dx.doi.org/10.1136/ annrheumdis-2015-209087)

For numbered affiliations see end of article.

\section{Correspondence to}

Professor Christopher P Denton, Centre for Rheumatology, UCL Division of Medicine, Rowland Hill Street, London NW3 2PF, UK; c.denton@ucl.ac.uk

Received 24 December 2015 Revised 1 July 2016

Accepted 3 July 2016 Published Online First 25 July 2016
CrossMark

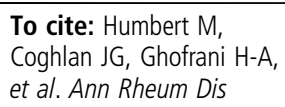

To cite: Humbert $\mathrm{M}$, Coghlan JG, Ghofrani H-A, et al. Ann Rheum Dis 2017;76:422-426.

\section{ABSTRACT}

Background The 12-week, phase III Pulmonary Arterial hyperTENsion sGC-stimulator Trial (PATENT)-1 study investigated riociguat in patients with pulmonary arterial hypertension (PAH). Here, we present a prospectively planned analysis of the safety and efficacy of riociguat in the subgroup of patients with $\mathrm{PAH}$ associated with connective tissue disease (PAH-CTD). Methods Patients with PAH-CTD were further classified post hoc as having PAH associated with systemic sclerosis or PAH-other defined CTD. In PATENT-1, patients received riociguat (maximum 2.5 or $1.5 \mathrm{mg}$ three times daily) or placebo. Efficacy endpoints included change from baseline in 6-minute walking distance (6MWD; primary endpoint), haemodynamics and WHO functional class (WHO FC). In the long-term extension PATENT-2, patients received riociguat (maximum $2.5 \mathrm{mg}$ three times daily); the primary endpoint was safety and tolerability.

Results In patients with PAH-CTD, riociguat increased mean 6MWD, WHO FC, pulmonary vascular resistance and cardiac index. Improvements in 6MWD and WHO FC persisted at 2 years. Two-year survival of patients with PAH-CTD was the same as for idiopathic PAH (93\%). Riociguat had a similar safety profile in patients with PAH-CTD to that of the overall population.

Conclusions Riociguat was well tolerated and associated with positive trends in 6MWD and other endpoints that were sustained at 2 years in patients with PAH-CTD.

Trial registration numbers PATENT-1 (NCT00810693), PATENT-2 (NCT00863681).

\section{INTRODUCTION}

Pulmonary arterial hypertension (PAH) is a complication of connective tissue disease (CTD) that results from remodelling of the pulmonary vasculature, ultimately leading to right ventricular failure and death. ${ }^{1-3}$ Many CTDs can lead to the development of $\mathrm{PAH}$ (PAH-CTD), including systemic sclerosis (SSc), systemic lupus erythematosus (SLE) and mixed CTD. ${ }^{4}$ Patients with PAH-CTD have a poorer prognosis compared with patients with idiopathic PAH (IPAH), and patients with $\mathrm{PAH}$ associated with SSc (PAH-SSc) have worse survival rates than those with non-SSc PAH-CTD..$^{5-7}$

Recommended treatments for PAH-CTD include prostanoids, phosphodiesterase type 5 (PDE5) inhibitors and endothelin receptor antagonists (ERAs). However, the response to PAH-specific therapy is often reduced in patients with PAH-CTD (particularly PAH-SSc) compared with IPAH. ${ }^{8} 9$

Riociguat, a soluble guanylate cyclase stimulator, is approved for the treatment of PAH. In addition to its vasoactive properties, riociguat has been shown to have antifibrotic, antiproliferative and antiinflammatory effects in preclinical models, providing a rationale for its use in PAH-CTD. ${ }^{10-14}$ In the phase III Pulmonary Arterial hyperTENsion sGCstimulator Trial (PATENT)-1 study (NCT00810693) in patients with $\mathrm{PAH}$ of various aetiologies, including patients with PAH-CTD, riociguat was well tolerated and improved 6-minute walking distance (6MWD) and several secondary outcomes. ${ }^{15}$ The improvements in 6MWD and WHO functional class (WHO FC) were maintained at 2 years in the PATENT-2 open-label extension (NCT00863681). ${ }^{16}$ Here, we present a prospectively planned analysis of the safety and efficacy of riociguat in the subgroup of patients with PAH-CTD in PATENT-1 and PATENT-2.

\section{METHODS}

Patients, study design and outcome measures The methodologies of the PATENT-1 and PATENT-2 studies are summarised in the online supplementary appendix. Patients in the prospectively defined $\mathrm{PAH}-$ CTD subgroup were stratified into three subgroups (PAH-SSc, PAH-other defined CTD and PAHunspecified CTD) based on MedDRA terms in their medical history.

\section{Statistical analysis}

All analyses were exploratory as PATENT-1 was not powered to detect significant differences in subgroups; all data were analysed descriptively. The primary efficacy analysis was performed on data from the modified intention-to-treat population (all randomised patients who received at least one dose of study drug). The primary endpoint (6MWD) was analysed by analysis of covariance to estimate the least-squares (LS) mean difference and 95\% CIs for riociguat $2.5 \mathrm{mg}$ maximum versus placebo in the PAH-CTD population. Missing data due to patient withdrawal or death were imputed at week 12 of PATENT-1 as previously described, ${ }^{15}$ except for haemodynamic endpoints, which were not imputed. 


\section{RESULTS}

\section{Patients and baseline characteristics}

Of the 443 patients randomised and treated in PATENT-1, 111 patients had PAH-CTD, of whom 66 had PAH-SSc and 39 had PAH-other defined CTD (18 associated with SLE; 11 associated with rheumatoid arthritis/disorder; 10 associated with mixed/ other CTD), and 6 had PAH associated with an unspecified CTD, as further medical history data were not available. Owing to low patient numbers, data are not shown for patients with $\mathrm{PAH}$ associated with an unspecified CTD.

Demographics, baseline characteristics and background therapy for patients with PAH-CTD in PATENT-1 are shown in table 1. Patient disposition for the subgroup with PAH-CTD in PATENT-1 is shown in online supplementary figure S1. Of the 111 patients with PAH-CTD in PATENT-1, 94 (85\%) completed PATENT-1 and entered PATENT-2. Mean \pm SD treatment duration for the PAH-CTD population in PATENT-2 was $31 \pm 14$ months. For the PAH-SSc and PAH-other defined CTD subgroups, mean treatment duration was $29 \pm 15$ months and $35 \pm 12$ months, respectively.

\section{Efficacy}

\section{The $2.5 \mathrm{mg}$ maximum group}

In the PAH-CTD population at week 12 , riociguat $2.5 \mathrm{mg}$ maximum increased mean \pm SD $6 \mathrm{MWD}$ by $+18 \pm 51 \mathrm{~m}$ compared with a decrease of $-8 \pm 110 \mathrm{~m}$ in the placebo group (see online supplementary figure S2A) (LS mean treatment difference: $+28 \mathrm{~m}$; 95\% CI -4 to $61 \mathrm{~m})$. Patients with PAH-SSc

\begin{tabular}{|c|c|c|c|}
\hline Characteristic & $\begin{array}{l}\text { Overall } \\
\text { PAH-CTD } \\
(\mathrm{n}=111)\end{array}$ & $\begin{array}{l}\text { PAH-SSC } \\
(n=66)\end{array}$ & $\begin{array}{l}\text { PAH-other } \\
\text { defined CTD } \\
\text { ( } n=39)\end{array}$ \\
\hline Age, mean $\pm S D$ (years) & $57 \pm 14$ & $63 \pm 11$ & $50 \pm 14$ \\
\hline Female, n (\%) & $98(88)$ & $57(86)$ & $36(92)$ \\
\hline $\begin{array}{l}\text { Time from first diagnosis of } \mathrm{PH}, \\
\text { mean } \pm \mathrm{SD} \text { (months) }\end{array}$ & $27 \pm 36$ & $26 \pm 35$ & $26 \pm 38$ \\
\hline $6 \mathrm{MWD}$, mean $\pm S D(\mathrm{~m})$ & $352 \pm 75$ & $340 \pm 76$ & $364 \pm 74$ \\
\hline WHO FC I/II/III/IV (\%)* & $5 / 36 / 57 / 2 \dagger$ & $2 / 35 / 59 / 3 \dagger$ & $10 / 36 / 54 / 0$ \\
\hline PAH-specific pretreatment, n (\%) & $70(63)$ & $45(68)$ & $23(59)$ \\
\hline Pretreated with ERA & $59(53)$ & $39(59)$ & $19(49)$ \\
\hline Pretreated with PCA & $10(9)$ & $6(9)$ & $3(8)$ \\
\hline Pretreated with ERA and PCA & $1(1)$ & 0 & $1(3)$ \\
\hline $\begin{array}{l}\text { Immunomodulating pretreatment, } \\
\mathrm{n}(\%) \ddagger\end{array}$ & $27(24)$ & $16(24)$ & $10(26)$ \\
\hline $\begin{array}{l}\text { Pretreated with } \\
\text { immunosuppressive agents§ }\end{array}$ & $21(19)$ & $13(20)$ & $8(21)$ \\
\hline $\begin{array}{l}\text { Pretreated with antineoplastic } \\
\text { agents } \Uparrow\end{array}$ & $14(13)$ & $6(9)$ & $7(18)$ \\
\hline $\begin{array}{l}\text { Pretreated with endocrine } \\
\text { therapy** }\end{array}$ & $1(1)$ & $1(2)$ & 0 \\
\hline $\begin{array}{l}\text { Pretreated with other } \\
\text { immunomodulating agents }\end{array}$ & $1(1)$ & 0 & 1 (3) \\
\hline
\end{tabular}

\footnotetext{
*Not all percentages add up to 100 due to rounding.

†Data missing for one patient.

$\ddagger$ Non-steroidal anti-inflammatory drugs or disease-modifying antirheumatic drugs.

$\S$ Azathioprine, leflunomide, methotrexate, mizoribine, mycophenolate mofetil, mycophenolate sodium, tacrolimus.

१Celecoxib, cyclophosphamide, methotrexate.

**Estradiol valerate.

6MWD, 6-minute walking distance; CTD, connective tissue disease; ERA, endothelin receptor antagonist; PAH, pulmonary arterial hypertension; PCA, prostacyclin analogue; $\mathrm{PH}$, pulmonary hypertension; SSc, systemic sclerosis; WHO FC, WHO functional class.
}

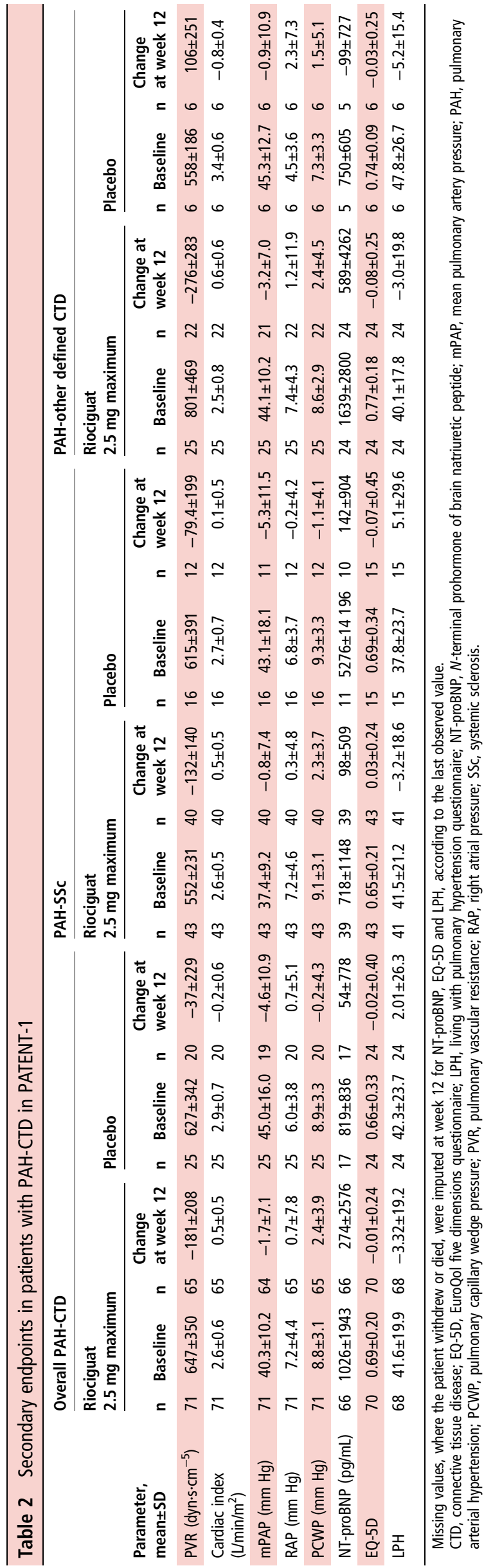


receiving riociguat reported a smaller increase in 6MWD $(+4$ $\pm 43 \mathrm{~m}$ ), but there was a larger decrease in the placebo group $(-37 \pm 120 \mathrm{~m})$ at week 12 (LS mean difference: $+43 \mathrm{~m}$; 95\% CI 1 to $86 \mathrm{~m}$ ) (see online supplementary figure S2B). The PAH-other defined CTD subgroup showed similar improvements in the riociguat and placebo groups at week 12 (see online supplementary figure S2C). Patients who were treatmentnaive, pretreated and patients with concomitant immunosuppressant use showed similar changes from baseline in mean $\pm S D$ $6 \mathrm{MWD}$ at week $12(21 \pm 53,17 \pm 50$ and $14 \pm 63$, respectively, see online supplementary tables S1 and S2). In PATENT-2, improvements in 6MWD were largely maintained at 2 years in the PAH-CTD, PAH-SSc and PAH-other defined CTD groups (see online supplementary figure S3).

At week 12 in the PAH-CTD population, the proportion of patients in whom WHO FC had improved or stabilised was $97 \%$ in the riociguat group versus $75 \%$ in the placebo group (see online supplementary figure S4). Results were similar in the PAH-SSc and PAH-other defined CTD subgroups (see online supplementary figure S4). At 2 years of PATENT-2, WHO FC had improved/stabilised/worsened in 36\%/59\%/6\% of patients in the PAH-CTD population.

Haemodynamics, $N$-terminal prohormone of brain natriuretic peptide (NT-proBNP) and quality-of-life endpoints are shown in table 2. Riociguat improved pulmonary vascular resistance (PVR) and cardiac index to a greater extent versus placebo in the PAH-CTD population (table 2); similar results were seen in the PAH-SSc and PAH-other defined CTD subgroups, although the effect was less pronounced in the PAH-SSc subgroup. No conclusive differences were observed for changes in mean pulmonary arterial pressure, right atrial pressure and pulmonary capillary wedge pressure. The efficacy endpoints for riociguat $2.5 \mathrm{mg}$ maximum from baseline to week 12 in patients with PAH-CTD who required extra PAH treatment during PATENT-2 are shown in online supplementary table S3.

As patients with morphea may not have systemic disease, a sensitivity analysis was performed, excluding three patients described as having morphea. The results showed similar values across the main efficacy endpoints to those seen in the overall PAH-CTD population (see online supplementary table S4).

\section{The $1.5 \mathrm{mg}$ maximum group}

Changes in efficacy endpoints in patients with PAH-CTD in the exploratory riociguat $1.5 \mathrm{mg}$ maximum group are shown in online supplementary table S5.

\section{Clinical worsening}

In PATENT-2, clinical worsening (hospitalisation, decrease in 6MWD or persistent worsening of WHO FC due to pulmonary hypertension $(\mathrm{PH})$, start of new $\mathrm{PH}$ treatment or death) occurred in $29 \%$ of patients with PAH-CTD (see online supplementary figure S5) with events occurring more frequently in the PAH-SSc subgroup (33\%) compared with the PAH-other defined CTD subgroup (24\%). Twelve (13\%) deaths occurred in the PAH-CTD population in PATENT-2, six $(6 \%)$ of whom had PAH-SSc. At 2 years, survival rates for patients with idiopathic/ familial PAH and PAH-CTD were both 93\% (see online supplementary figure S6).

\section{Safety}

Adverse events (AEs) and serious adverse events (SAEs) occurring in the PAH-CTD population during PATENT-1 are shown in table 3. The frequency of AEs was comparable in the PAH-CTD population and the subgroups. No cases of haemoptysis or pulmonary haemorrhage occurred in patients with PAH-CTD in PATENT-1. One (1\%) death, resulting from

\begin{tabular}{|c|c|c|c|c|c|c|c|c|}
\hline & \multicolumn{2}{|l|}{ Overall PATENT-1 } & \multicolumn{2}{|c|}{ Overall PAH-CTD } & \multicolumn{2}{|l|}{ PAH-SSC } & \multicolumn{2}{|c|}{ PAH-other defined CTD } \\
\hline & $\begin{array}{l}\text { Riociguat (all } \\
\text { doses) }(n=317)\end{array}$ & $\begin{array}{l}\text { Placebo } \\
(n=126)\end{array}$ & $\begin{array}{l}\text { Riociguat (all } \\
\text { doses) }(n=86)\end{array}$ & $\begin{array}{l}\text { Placebo } \\
(n=25)\end{array}$ & $\begin{array}{l}\text { Riociguat (all } \\
\text { doses) }(n=50)\end{array}$ & $\begin{array}{l}\text { Placebo } \\
(n=16)\end{array}$ & $\begin{array}{l}\text { Riociguat (all } \\
\text { doses) }(n=33)\end{array}$ & $\begin{array}{l}\text { Placebo } \\
(n=6)\end{array}$ \\
\hline Any $A E$ & $285(90)$ & $108(86)$ & $82(95)$ & $24(96)$ & $49(98)$ & $15(94)$ & $30(91)$ & $6(100)$ \\
\hline \multicolumn{9}{|c|}{ AEs experienced by $\geq 20 \%$ patients in any CTD group } \\
\hline Headache & $89(28)$ & $25(20)$ & $26(30)$ & $9(36)$ & $16(32)$ & $8(50)$ & $7(21)$ & 1 (17) \\
\hline Peripheral oedema & $58(18)$ & $14(11)$ & $16(19)$ & $5(20)$ & $11(22)$ & $2(13)$ & $5(15)$ & $2(33)$ \\
\hline Dizziness & $55(17)$ & $15(12)$ & $15(17)$ & $3(12)$ & $12(24)$ & $1(6)$ & $3(9)$ & $1(17)$ \\
\hline Diarrhoea & $41(13)$ & $13(10)$ & $13(15)$ & $6(24)$ & $9(18)$ & $4(25)$ & $3(9)$ & $1(17)$ \\
\hline Anaemia & $22(7)$ & $3(2)$ & $12(14)$ & $3(12)$ & $10(20)$ & $2(13)$ & $2(6)$ & $1(17)$ \\
\hline Pyrexia & $14(4)$ & $4(3)$ & $10(12)$ & $1(4)$ & $5(10)$ & 0 & $4(12)$ & $1(17)$ \\
\hline Discontinuation due to $\mathrm{AE}$ & $9(3)$ & $9(7)$ & $3(3)$ & $4(16)$ & $3(6)$ & $4(25)$ & 0 & 0 \\
\hline Any SAE & $40(13)$ & $23(18)$ & $14(16)$ & $7(28)$ & $10(20)$ & $5(31)$ & $4(12)$ & $2(33)$ \\
\hline \multicolumn{9}{|c|}{ SAEs experienced by $\geq 5 \%$ patients in any CTD group } \\
\hline Right ventricular failure & $5(2)$ & $1(1)$ & $2(2)$ & $1(4)$ & $1(2)$ & $1(6)$ & $1(3)$ & 0 \\
\hline Dyspnoea & 0 & $1(1)$ & 0 & $1(4)$ & 0 & $1(6)$ & 0 & 0 \\
\hline Worsening PAH & $2(1)$ & $2(2)$ & 0 & $2(8)$ & 0 & $2(13)$ & 0 & 0 \\
\hline Discontinuation due to SAE & $5(2)$ & $7(6)$ & $1(1)$ & $3(12)$ & $1(2)$ & $3(19)$ & 0 & 0 \\
\hline Deaths & $3(1)$ & $3(2)$ & 0 & $1(4)$ & 0 & $1(6)$ & 0 & 0 \\
\hline
\end{tabular}

$\mathrm{AE}$, adverse event; CTD, connective tissue disease; PAH, pulmonary arterial hypertension; SAE, serious adverse event; SSC, systemic sclerosis 
worsening $\mathrm{PH}$, was reported in a patient with $\mathrm{PAH}-\mathrm{SS}$ c receiving placebo.

AEs, SAEs and discontinuations were similar for the overall PATENT-2 population and the PAH-CTD subgroup, although most AEs occurred more frequently in patients with PAH-CTD and patients with concomitant immunosuppressant use (see online supplementary table S6). The most common SAEs in the pooled riociguat groups in the PAH-CTD population were pneumonia $(3 \%)$ and right ventricular failure (2\%). In PATENT-2, 1 (1\%) patient with PAH-CTD experienced an SAE of haemoptysis compared with $13(3 \%)$ patients in the overall population. A similar safety profile to that of the PAH-CTD population was observed in the subgroups.

\section{DISCUSSION}

Riociguat improved several efficacy endpoints in patients with PAH-CTD including 6MWD, WHO FC, PVR and cardiac index, although improvements were less pronounced than in the overall PATENT-1 population. This is consistent with previous observations that patients with PAH-CTD respond less well to PAH-specific therapy than patients with IPAH. ${ }^{4}{ }^{6}$ The efficacy results presented in this analysis appear comparable with previous trials of patients with PAH-CTD treated with prostacyclins, ${ }^{17}$ ERAs $^{18}$ and PDE5 inhibitors, ${ }^{8}$ although comparison between trials requires caution.

Less pronounced improvements in 6MWD were seen in patients with PAH-SSc; however, significant deterioration was observed in the PAH-SSc placebo group, suggesting that riociguat may prevent worsening of $6 \mathrm{MWD}$ in these patients. A separate study investigating riociguat in diffuse cutaneous SSc is ongoing (NCT02283762).

The improvements in 6MWD observed in patients that were pretreated with ERAs (53\% of the PAH-CTD population) suggest that riociguat may provide additional therapeutic benefits in patients with PAH-CTD receiving ERAs, supporting the potential use of combination therapy in this subgroup.

With over 2 years of riociguat treatment in PATENT-2, survival of patients with PAH-CTD was similar to that seen in patients with idiopathic/familial PAH in PATENT-2 (93\%). ${ }^{16}$ This is an important observation as mortality for PAH-CTD has been previously reported to be higher than IPAH despite modern therapy. ${ }^{19}$

The data in this analysis should be considered exploratory as PATENT-1 and PATENT-2 were not designed to detect statistically significant differences in subgroups. Moreover, the analysis is limited due to the post hoc subclassification of patients with PAH-CTD by patients' medical histories using MedDRA terms. Also, as with most long-term trial data, it is possible that the analyses of long-term outcomes are subject to survivor bias. Finally, the low patient numbers in the PAH-SSc and PAH-other defined CTD subgroups should be taken into consideration when interpreting the data.

In conclusion, riociguat was well tolerated in patients with PAH-CTD and led to improvement or stabilisation in 6MWD, WHO FC and haemodynamics. The 2-year survival rate of patients with PAH-CTD or PAH-SSc was similar to that of patients with idiopathic/familial PAH.

\footnotetext{
Author affiliations

${ }^{1}$ Université Paris-Sud, Faculté de Médecine, Université Paris-Saclay, Le Kremlin Bicêtre, France

${ }^{2}$ AP-HP, Service de Pneumologie, Hôpital Bicêtre, Le Kremlin Bicêtre, France ${ }^{3}$ Inserm UMR_S 999, Hôpital Marie Lannelongue, Le Plessis Robinson, France ${ }^{4}$ Royal Free London NHS Foundation Trust, London, UK

${ }^{5}$ University of Giessen and Marburg Lung Center (member of the German Center of Lung Research (DZL)), Giessen, Germany
}

${ }^{6}$ Department of Medicine, Imperial College London, London, UK

${ }^{7}$ Chinese Academy of Medical Sciences and Peking Union Medical College, Beijing, China

${ }^{8}$ Department of Rheumatology, University of Lübeck, Lübeck, Germany

${ }^{9}$ La Sapienza University of Rome, Rome, Italy

${ }^{10}$ Bayer Pharma AG, Wuppertal, Germany

${ }^{11}$ Bayer Pharma AG, Berlin, Germany

${ }^{12}$ Bayer HealthCare Pharmaceuticals Inc, Whippany, New Jersey, USA

${ }^{13}$ University College London, Royal Free Campus, London, UK

Contributors $\mathrm{MH}, \mathrm{JGC}, \mathrm{H}-\mathrm{AG}, \mathrm{FG}, \mathrm{J}-\mathrm{GH}$ and CDV were PATENT-1 investigators directly involved in the recruitment and care of the participants; CPD, MH and CM contributed to the post hoc classification of patients; all authors contributed to the analysis and interpretation of the data, and contributed to the writing and revision of the manuscript for intellectual content, and have reviewed and approved the final version for submission.

Funding This study was supported by Bayer Pharma AG, Berlin, Germany. Editorial support was provided by Adelphi Communications Ltd, Bollington, UK, supported by Bayer Pharma AG.

Competing interests $\mathrm{MH}$ has received grants or fees for congress participation, advisory and expert board meetings, and/or research from Actelion, Bayer, GSK, Novartis and Pfizer, all related to the development of drugs in the field of pulmonary hypertension. CPD has been a consultant to Bayer, Roche, GSK, Actelion, Inventiva, CSL Behring, Takeda, Merck-Serono, Medlmmune and Biogen. He has received research grants from Actelion, GSK, Novartis and CSL Behring. JGC has received consultancy fees and honoraria from Actelion, GSK, Bayer, United Therapeutics, Endotronics and Pfizer, and unrestricted grants from Actelion, and GSK. J-GH has received fees for participation in advisory boards from Bayer. CDV has received grants or fees for congress participation, advisory boards and research from Actelion, Bayer, GSK, Lilly, Pfizer, and UTEL. AB and CM are employees of Bayer Pharma AG. JdOP is an employee of Bayer HealthCare Pharmaceuticals.

Ethics approval The Institutional Review Board at each participating centre approved the protocol. Data were collected according to Good Clinical Practice guidelines at the investigation sites.

Provenance and peer review Not commissioned; externally peer reviewed.

Open Access This is an Open Access article distributed in accordance with the Creative Commons Attribution Non Commercial (CC BY-NC 4.0) license, which permits others to distribute, remix, adapt, build upon this work non-commercially, and license their derivative works on different terms, provided the original work is properly cited and the use is non-commercial. See: http://creativecommons.org/ licenses/by-nc/4.0/

\section{REFERENCES}

1 Galiè N, Humbert M, Vachiery JL, et al. 2015 ESC/ERS Guidelines for the diagnosis and treatment of pulmonary hypertension: The Joint Task Force for the Diagnosis and Treatment of Pulmonary Hypertension of the European Society of Cardiology (ESC) and the European Respiratory Society (ERS): Endorsed by: Association for European Paediatric and Congenital Cardiology (AEPC), International Society for Heart and Lung Transplantation (ISHLT). Eur Respir J 2015;46:903-75.

2 McLaughlin VV, Archer SL, Badesch DB, et al. ACCF/AHA 2009 expert consensus document on pulmonary hypertension: a report of the American College of Cardiology Foundation Task Force on Expert Consensus Documents and the American Heart Association: developed in collaboration with the American College of Chest Physicians, American Thoracic Society, Inc., and the Pulmonary Hypertension Association. Circulation 2009;119:2250-94.

3 Schermuly RT, Ghofrani HA, Wilkins MR, et al. Mechanisms of disease: pulmonary arterial hypertension. Nat Rev Cardiol 2011;8:443-55.

4 Mathai SC, Hassoun PM. Pulmonary arterial hypertension in connective tissue diseases. Heart Fail Clin 2012;8:413-25.

5 Humbert M, Sitbon 0, Yaïci A, et al. Survival in incident and prevalent cohorts of patients with pulmonary arterial hypertension. Eur Respir J 2010;36: 549-55.

6 Rhee RL, Gabler NB, Sangani S, et al. Comparison of treatment response in idiopathic and connective tissue disease-associated pulmonary arterial hypertension. Am J Respir Crit Care Med 2015;192:1111-17.

7 Chung L, Farber HW, Benza R, et al. Unique predictors of mortality in patients with pulmonary arterial hypertension associated with systemic sclerosis in the reveal registry. Chest 2014;146:1494-504.

8 Badesch DB, Hill NS, Burgess G, et al. Sildenafil for pulmonary arterial hypertension associated with connective tissue disease. J Rheumatol 2007;34:2417-22.

9 Denton CP, Humbert M, Rubin L, et al. Bosentan treatment for pulmonary arterial hypertension related to connective tissue disease: a subgroup analysis of the pivotal clinical trials and their open-label extensions. Ann Rheum Dis 2006;65:1336-40. 


\section{Clinical and epidemiological research}

10 Dees C, Beyer C, Distler A, et al. Stimulators of soluble guanylate cyclase (sGC) inhibit experimental skin fibrosis of different aetiologies. Ann Rheum Dis 2015;74:1621-5.

11 Geschka S, Kretschmer A, Sharkovska Y, et al. Soluble guanylate cyclase stimulation prevents fibrotic tissue remodeling and improves survival in salt-sensitive Dahl rats. PLoS One 2011;6:e21853.

12 Schermuly RT, Janssen W, Weissmann $\mathrm{N}$, et al. Riociguat for the treatment of pulmonary hypertension. Expert Opin Investig Drugs 2011;20:567-76.

13 Sharkovska Y, Kalk P, Lawrenz B, et al. Nitric oxide-independent stimulation of soluble guanylate cyclase reduces organ damage in experimental low-renin and high-renin models. J Hypertens 2010;28:1666-75.

14 Stasch JP, Evgenov OV. Soluble guanylate cyclase stimulators in pulmonary hypertension. Handb Exp Pharmacol 2013;218:279-313.

15 Ghofrani HA, Galiè N, Grimminger F, et al. Riociguat for the treatment of pulmonary arterial hypertension. N Engl I Med 2013;369:330-40.
16 Ghofrani HA, Grimminger F, Grünig E, et al. Predictors of long-term outcomes in patients treated with riociguat for pulmonary arterial hypertension: data from the PATENT-2 open-label, randomised, long-term extension trial. Lancet Respir Med 2016:4:361-71.

17 Badesch DB, Tapson VF, McGoon MD, et al. Continuous intravenous epoprostenol for pulmonary hypertension due to the scleroderma spectrum of disease. A randomized, controlled trial. Ann Intern Med 2000;132: $425-34$.

18 Denton CP, Pope JE, Peter HH, et al. Long-term effects of bosentan on quality of life, survival, safety and tolerability in pulmonary arterial hypertension related to connective tissue diseases. Ann Rheum Dis 2008;67:1222-8.

19 Chung L, Liu J, Parsons L, et al. Characterization of connective tissue disease-associated pulmonary arterial hypertension from REVEAL: identifying systemic sclerosis as a unique phenotype. Chest 2010;138:1383-94. 